\title{
Novel Antimicrobial Polyelectrolytes Nanofilm Coatings Using the Layer By Layer Technique
}

\author{
Mazen Khaled*, ${ }^{*}$, Basel Abu-Sharkh ${ }^{2}$, Amjad Khalil $^{3}$, Abdallah Manda $^{1}$ and Esam Amr ${ }^{2}$ \\ Department of ${ }^{1}$ Chemistry ${ }^{2}$ Chemical Engineering ${ }^{3}$ Physics, King Fahd University of Petroleum and Minerals, Dhahran \\ 31261, Saudi Arabia
}

\begin{abstract}
A novel method using the layer by layer (LBL) technique was investigated to deposit polyelectrolytes with antibacterial properties. A glass substrate was coated by a cationic biguanide followed by the anionic polystyrene sulfonate until a total of twenty layers were deposited. The layers thickness was measured by ellipsometry and the surface morphology was scanned by an atomic force microscope. The layers thickness reached $60 \mathrm{~nm}$. The coated and uncoated glass was immersed into tubes containing a nutrient broth media inoculated with Proteus sp., (a gram negative, rod, glucose fermenting bacteria) in a concentration of $\left(\sim 10^{5}\right.$ cells $\left./ \mathrm{mL}\right)$ and incubated at $37^{\circ} \mathrm{C}$ for 24 hours. The SEM (Scanning Electron Microscope) micrographs showed a significant reduction in the settlement of Proteus $s p$. Colonies on the glass coated with polyelectrolytes.
\end{abstract}

\section{INTRODUCTION}

Microorganism growth and spread is a very complex concern for many applications such as in medical products, packaging materials or filters used in air-conditioning systems [1-3]. Scientists developed many methods to reduce microbial transport such as disinfection. However, these methods suffer from being temporary solutions where after application of the sterilization methods, the surface will be subtle to microbial attack as soon as it is exposed. Disinfectants are chemical agents which kill microorganisms in short time, being usually used as solutions. Many macromolecules have been developed and showed excellent disinfecting and antibacterial activities. However, immobilizing these molecules for prolonged biocide effect was another challenging issue. Researchers developed polymeric macromolecules with antibacterial properties which was proved to be more efficient than the antibacterial monomer [4-6]. These polymers had quaternary ammonium salts, biguanide groups, quaternary pyridinium salts, sulphonium salts, phosphonium salts, and other antibacterial groups. Some researchers tried to immobilize these polymers synthetically which is demanding and commercially costly [7-9]. By immobilizing biocide groups, the surface will be protected against bacterial attachment for prolonged periods of time. One of the interesting techniques in thin films coating is the layer-by-layer (LBL) method $[10,11]$ based on electrostatic adsorption due to its experimental simplicity and flexibility in terms of the materials that can be used. The LBL method consists in adsorbing alternated cationic and anionic layers onto a solid substrate, Repetition of the steps may be performed to deposit typically up to hundreds of bilayers.

In this paper we report the first successful physical immobilization of biocide molecules on glass using polyelec-

*Address correspondence to this author at the Department of Chemistry, King Fahd University of Petroleum and Minerals, Dhahran 31261, Saudi Arabia; Tel: 0096638602454; Fax: 0096638604277;

E-mail: mkhaled@kfupm.edu.sa trolytes deposited by the layer by layer method [12]. The method is independent of the chemical nature of the surface and can be versatile in its application.

\section{MATERIALS AND METHODOLOGY}

\section{Film Deposition on Glass Support}

Polystyrene sulfonate of molar mass 70,000 $\mathrm{gmol}^{-1}$, Fig. (1a), an anionic agent was purchased from Aldrich. Poly(hexamethylenebiguanide hydrochloride, Fig. (1b), a well known antibacterial and cationic agent was purchased from Cytec as Talocide CS. Aqueous solution of $1 \mathrm{mM}$ concentration was used for both. Glass substrates of $2 \mathrm{~cm} \times 5 \mathrm{~cm}$ was coated using StratoSequence VI from NanoStrata Inc. after cleaning with a mixture of hydrogen peroxide and sulfuric acid 1:3 (v:v). The StratoSequence VI consists of a circular robotic platform with spaces for eight $100 \mathrm{~mL}$ or $150 \mathrm{~mL}$ beakers. The platform is raised and lowered by means of a compressed air cylinder. A special mechanism (US Patent \# 6,460,424 B1) translates the up-down motion to a lateral motion in a very reliable way. The sample is held static and the solutions come up to meet the sample. The glass substrates were immersed in the PE solution for five minutes while spinning at a rate of $300 \mathrm{rpm}$. Then they were subsequently rinsed for 90 seconds using deionized water in three different beakers, 30 seconds in each. The spinning and rinsing was repeated to obtain 20 layers of the biguanide/PSS system.

\section{AFM Imaging}

Force measurements of the multilayer films were performed using a $5100 \mathrm{AFM} / \mathrm{SPM}$ Microscope by Agilent in contact mode. The tip was made of silicon nitride probes $(\mathrm{r}=$ 20-60 nm) with a manufacturer specified force constant, $\mathrm{k}$, of $0.12 \mathrm{~N} / \mathrm{m}$.

\section{Film Thickness}

The measurement of film thickness was carried out using the stokes ellipsometer LSE by Gaertner Scientific Corpora- 
<smiles>CCCC(C)c1ccc(S(=O)(=O)O)cc1</smiles>

a. PSS

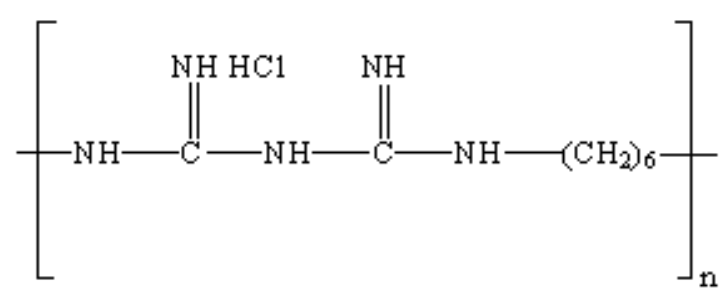

b. Biguanide

Fig. (1). Repeat unit structures of the anionic PSS and cationic biguanide hydrochloride.

tion. The LSE ellipsometer uses patented StokesMeter technology with no moving parts and no modulators to quickly and accurately determine the complete polarization state of the $6328 \AA \mathrm{HeNe}$ laser measuring beam at a $70^{\circ}$ incidence angle. All total layer thickness values are reported as the statistical mean of 13 acquired measurements.

\section{Bacterial Cultivation and Microscopy}

A glass slide, coated with a (Biguanide/PSS) film was immersed into tubes containing a nutrient broth media inoculated with Proteus sp., (a gram negative , rod, glucose fermenting bacteria in a concentration of $\left(\sim 10^{5}\right.$ cells $\left./ \mathrm{mL}\right)$ and incubated at $37^{\circ} \mathrm{C}$ for 24 hours. The slide was then dried gradually at room temperature. The same procedure was repeated with non coated glass slides. For SEM analysis the glass was coated with gold. The glass slides were then observed under a scanning electron microscope. SEM was performed on a JEOL $5900 \mathrm{LV}$ scanning electron microscope operating at $15 \mathrm{kV}$.

\section{RESULTS AND DISCUSSION}

Multilayers films of polyelectrolytes complexes may be coated on different substrates by alternate exposure to solutions of oppositely charged soluble polymers [13-16]. The multilayers have a general amorphous and structure due to interpenetration of polymer molecules and $[17,18]$ and they have shown exceptional promise as selective membranes for the controlled transport [19] and release [20] of small molecules and for the immobilization of biomacromolecules [21] or particles [22].

Quaternary ammonium salt polymeric compounds are known for their large biocidal effect. They are believed to adsorb on the negatively charged cell surfaces by electrostatic interaction, followed by the diffusion of the long alkyl chain through the cell wall. This results in a weakening of the cytoplasmic membrane, leading to a leakage of cytoplasmic contents and eventual death of the cell.

Multilayers of the quaternary ammonium polymer biguanide and the anionic polystyrene sulfonate (PSS) were deposited on glass substrates. The layers thickness measured by ellipsometry is shown in Fig. (2). The thickness of the twenty layers was $60 \mathrm{~nm}$. Fig. (3a and $\mathbf{3 b}$ ) shows an AFM photos of bare glass and glass coated with the biguanide/PSS system respectively.

The antimicrobial activity of glass coated with biguanide/PSS was investigated by adhesion test. Fig. (4) shows the SEM photos of the uncoated glass and the glass coated with 20 layers of the biguanide/PSS system. The biguanide/PSS layers reduce the settlement of Proteus sp. colonies significantly. Fig. (4b) shows clearly a population reduction in the count of the Proteus sp. compared to Fig. (4a) which shows dense bacteria population grown on glass substrates. Oliveira et al. showed that the insertion of $\mathrm{TiO}_{2}$ nanoparti-

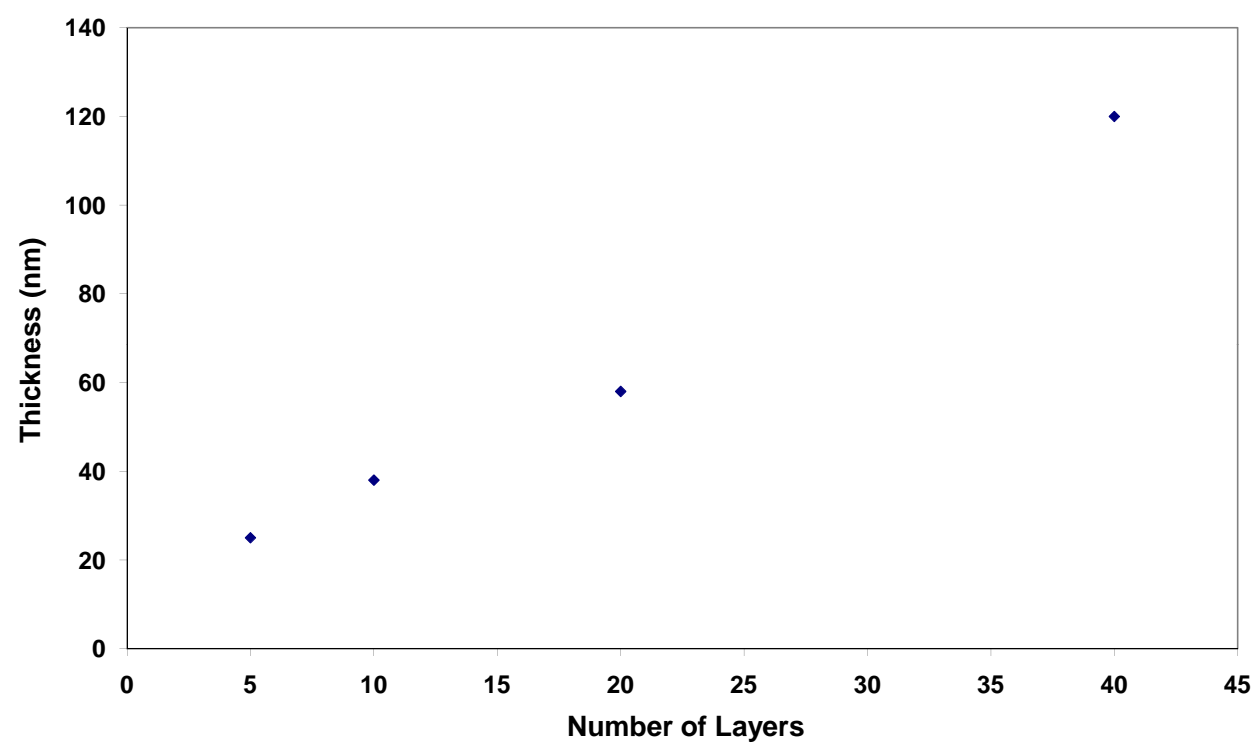

Fig. (2). Thickness of the multilayers measured by the LSE ellipsometer. 


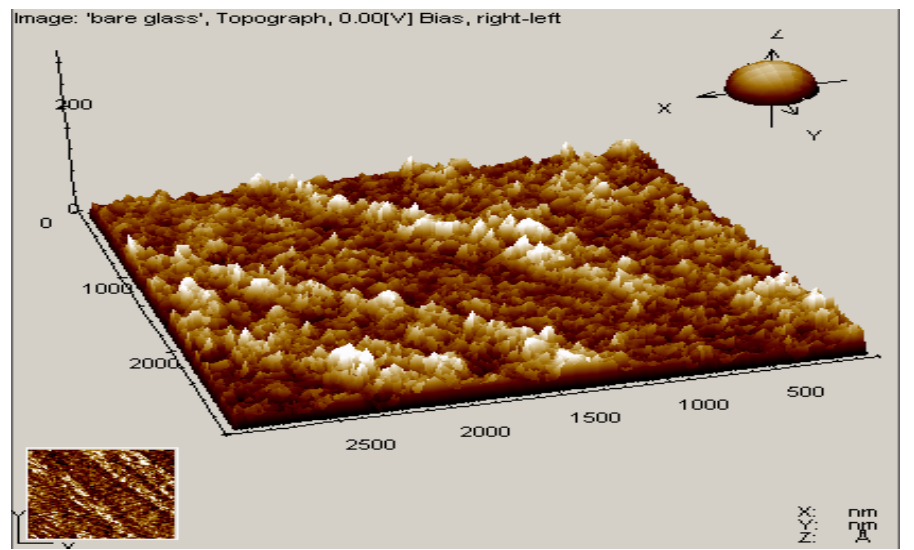

(a)

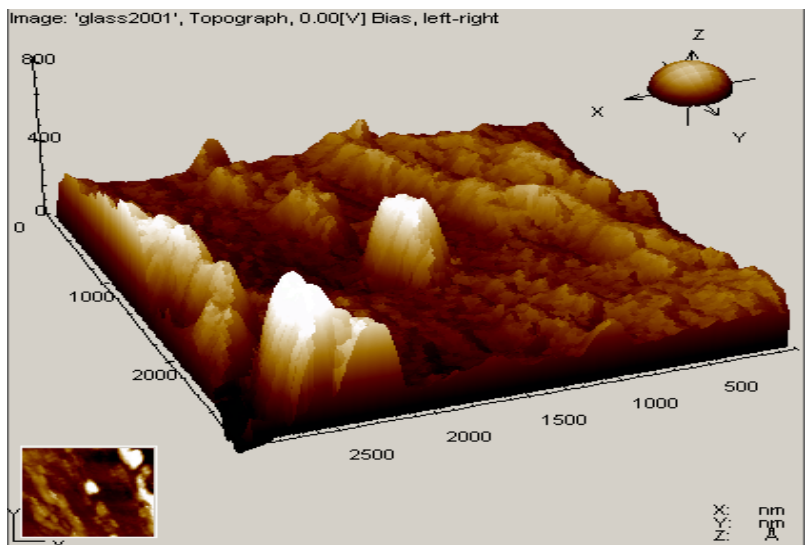

(b)

Fig. (3). AFM photos of (a) bare glass and (b) glass coated with twenty multilayers of biguanide/PSS system.

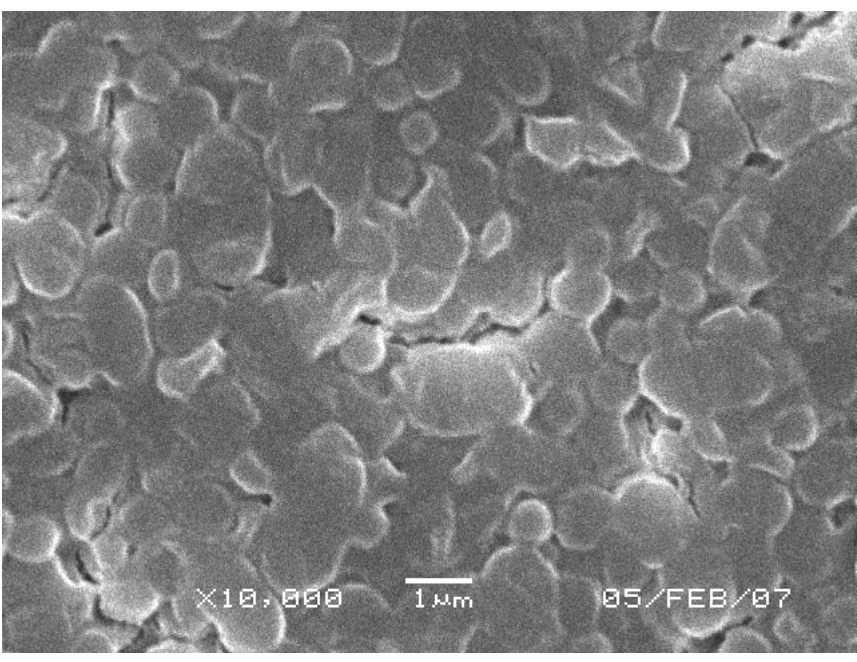

(a)

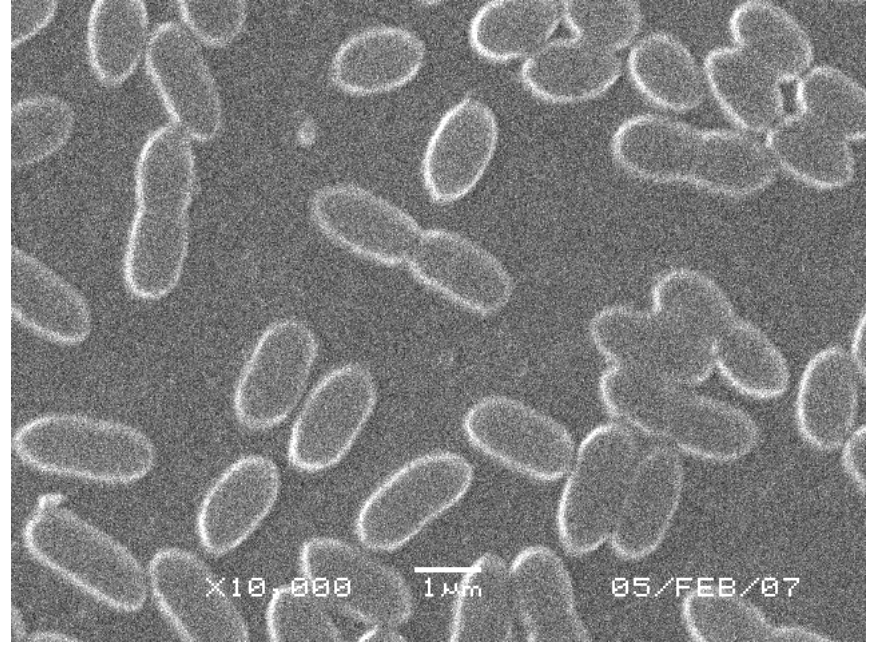

(b)

Fig. (4). SEM micrographs of bacteria grown on (a) uncoated glass and (b) glass coated with 20 layers of the biguanide/PSS system.

cles with PDADMA generated a rough multilayer surface. Enhancement in stem cells adhesion and proliferationwas observed to be a direct consequence of increased surface roughness [23]. This correlates with our observation of significant reduction in bacterial growth on the irregular substrate surface shown in Fig. (3).

Hence, biguanide has been utilized widely in solution as an effective antimicrobial agent, however, it is the first time to be immobilized by the LBL method and tested for biocide effect.

\section{CONCLUSION}

This paper presented a new strategy to immobilize antibacterial compounds based on the layer by layer method. The multilayers composed of biguanide/PSS with a thickness of approximately $50 \mathrm{~nm}$ was sufficient to cause a significant reduction in colony number of the Proteus sp. This antibacterial coating technology is very promising in a wide range of medical and industrial applications. Using such application in the health care system will have a significant impact on lowering hospital-acquired infection rates. It is a top priority for healthcare professionals when it comes to patient safety. Adding an antimicrobial coating is a convenient and cost-effective way of further improving patient safety and reducing the spread of infections throughout the hospital. Further investigations are underway to elucidate the mechanism of adsorption and the effect of different parameters on the biocide activity.

\section{ACKNOWLEDGMENTS}

The authors acknowledge KFUPM especially the medical clinic, the environment lab of the civil engineering department, the SEM facility of the Earth Sciences department.

\section{REFERENCES}

[1] Livermore DM, Macgowan AP, Wale MCJ. Surveillance of antimicrobial resistance. Br Med J 1998; 317: 614-5.

[2] Bach A, Schmidt H, Bottiger B, et al. Retention of antibacterial activity and bacterial colonization of antiseptic-bonded central venous catheters. J Antimicrob Chemother 1996; 37: 315-22.

[3] Demain AL, Davies JE, Atlas RM, Cohen G. Manual of Industrial Microbiology and Biotechnology. $2^{\text {nd }} e d$. ASM Press; 1999.

[4] Tashiro T. Antibacterial and bacterium adsorbing macromolecules. Macromol Mater Eng 2001; 286(2): 63-87. 
[5] Dizman B, Elasri MO, Mathias LJ. Synthesis, characterization, and antibacterial activities of novel methacrylate polymers containing norfloxacin. Biomacromolecules 2005; 6: 514-520.

[6] Cakmak I, Ulukanli Z, Tuzcu M, Karabuga S, Genctav K. Synthesis and characterization of novel antimicrobial cationic polyelectrolytes. Eur Polym J 2004; 40(10): 2373-79.

[7] Oliphant CM, Green GM. Quinolones: A comprehensive review. Am Fam Physician 2002; 65(3): 455-64.

[8] Iconomopouloua SM, Andreopouloua AK, Sotoa A, Kallitsisa JK, VoyiatzisHazziza-Laskar GA. Incorporation of low molecular weight biocides into polystyrene-divinyl benzene beads with controlled release characteristics. J Control Release Sci 2005; 102: 223-33.

[9] Decher HG. Fuzzy Nanoassemblies: Toward layered polymeric multicomposites. Science 1997; 277/5330: 1232-7.

[10] Decher HG, Hong JD, Schmitt J. Interfacial behaviour of polyelectrolyte-nanoparticle systems. Thin Solid Films 1992; 210/211: 8315 .

[11] Jaber J, Schlenoff B. Recent developments in the properties and applications of polyelectrolyte multilayers. Curr Opin Colloid Interface Sci 2006; 11: 324-9.

[12] Khaled M, Abu-Sharkh B. Pending patent application US11/ 404,025, 2006.

[13] Decher HG, Schlenoff JB, Eds. Multilayer Thin Films-Sequential Assembly of Nanocomposite Materials. Wiley-VCH: Weinheim 2002.

[14] Hyde K, Rusa M, Hinestrozal J. Layer-by-layer deposition of polyelectrolyte nanolayers on natural fibres: Cotton. Nanotechnology $2005 ; 16$ : S422-8.
[15] Decher HG. In: Sauvage JP, Hosseini MW Eds. Comprehensive Supramolecular Chemistry. Pergamon Press: Oxford, 1996; Chapter 14 , vol. 9

[16] Bertrand P, Jonas A, Laschewsky A, Legras R. Ultrathin polymer coatings by complexation of polyelectrolytes at interfaces: Suitable materials, structure and properties. Macromol Rapid Commun 2000; 21: 319-48.

[17] Schlenoff JB, Ly H, Li M. Charge and mass balance in polyelectrolyte multilayers. J Am Chem Soc 1998; 120: 7626-34.

[18] Bixler HJ, Michaels A. Encylcopedia of Polymer Science and Technology; Interscience: New York, 1969; vol. 10: p. 765.

[19] Harris JJ, Bruening ML. Electrochemical and in situ ellipsometric investigation of the permeability and stability of layered polyelectrolyte films. Langmuir 2000; 16: 2006-13.

[20] Chung AJ, Rubner MF. Methods of loading and releasing low molecular weight cationic molecules in weak polyelectrolyte multilayer films. Langmuir 2002; 18: 1176-83.

[21] Decher G, Lehr B, Lowack K, Lvov Y, Schmitt J. New nanocomposite films for biosensors: layer-by-layer adsorbed films of polyelectrolytes, proteins or DNA. Biosens Bioelectron 1994; 9: 677-84.

[22] Kotov NA, Dekany I, Fendler JH. Layer-by-layer self-assembly of polyelectrolyte-semiconductor nanoparticle composite films. J Phys Chem 1995; 99: 13065-69.

[23] Raposo M, Oliveira ON. Adsorption of poly(o-methoxyaniline) in layer-by layer films. Langmuir 2002; 18(18): 6866-74.

Received: August 26, 2008

Revised: October 08, 2008

Accepted: October 09, 2008

(c) Khaled et al.; Licensee Bentham Open.

This is an open access article licensed under the terms of the Creative Commons Attribution Non-Commercial License (http://creativecommons.org/licenses/by-nc/3.0/) which permits unrestricted, non-commercial use, distribution and reproduction in any medium, provided the work is properly cited. 